\title{
Migraine aura, a predictor of near-death experiences in a crowdsourced study
}

\author{
Daniel Kondziella ${ }^{\text {Corresp., 1, } 2 \text {, Markus Harboe Olsen }}{ }^{3}$, Coline Lemale ${ }^{4,5}$, Jens P. Dreier ${ }^{4,5,6,7,8}$ \\ ${ }^{1}$ Department of Neurology, Rigshospitalet, Copenhagen University Hospital, Copenhagen, Denmark \\ 2 Faculty of Health and Medical Sciences, University of Copenhagen, Copenhagen, Denmark \\ 3 Department of Neuroanesthesiology, Rigshospitalet, Copenhagen University Hospital, Copenhagen, Denmark \\ 4 Department of Neurology, Charité - Universitätsmedizin Berlin, Freie Universität Berlin, Humboldt-Universität zu Berlin, Berlin Institute of Health, Berlin, \\ Germany \\ ${ }^{5}$ Center for Stroke Research Berlin, Charité - Universitätsmedizin Berlin, Freie Universität Berlin, Humboldt-Universität zu Berlin, Berlin Institute of Health, \\ Berlin, Germany \\ 6 Department of Experimental Neurology, Charité - Universitätsmedizin Berlin, Freie Universität Berlin, Humboldt-Universität zu Berlin, Berlin Institute of \\ Health, Berlin, Germany \\ 7 Bernstein Center for Computational Neuroscience Berlin, Berlin, Germany \\ 8 Einstein Center for Neurosciences Berlin, Berlin, Germany \\ Corresponding Author: Daniel Kondziella \\ Email address: daniel_kondziella@yahoo.com
}

Background: Near-death experiences (NDE) occur with imminent death and in situations of stress and danger but are poorly understood. Evidence suggests that NDE are associated with rapid eye movement (REM) sleep intrusion, a feature of narcolepsy. Previous studies further found REM abnormalities and an increased frequency of dream-enacting behavior in migraine patients, as well as an association between migraine with aura and narcolepsy. We therefore investigated if NDE are more common in people with migraine aura.

Methods: We recruited 1037 laypeople from 35 countries and 5 continents, without any filters except for English language and age $\geq 18$ years, via a crowdsourcing platform. Reports were validated using the Greyson NDE Scale.

Results: Eighty-one of 1037 participants had NDE (7.8\%; Cl 6.3-9.7\%). There were no significant associations between NDE and age ( $p>0.6$, t-test independent samples) or gender ( $p>0.9$, chi-square test). The only significant association was between NDE and migraine aura: Forty-eight (6.1\%) of 783 subjects without migraine aura and $33(13.0 \%)$ of 254 subjects with migraine aura had NDE $(p<0.001$, chi-square test, odds ratio $(O R)=2.29)$. In multiple logistic regression analysis, migraine aura remained significant after adjustment for age $(p<0.001$, OR 2.31), gender $(p<0.001$, OR 2.33), or both $(p<0.001$, OR 2.33).

Conclusions: In our sample, migraine aura was a predictor of NDE. This indirectly supports the association between NDE and REM intrusion and might have implications for the understanding of NDE, because a variant of spreading depolarization (SD), terminal SD, occurs in humans at the end of life, while a short-lasting variant of SD is considered the pathophysiological correlate of migraine aura. 
1

2

3

4

5

6

7

8

9

10

\title{
Migraine aura, a predictor of near-death experiences in a crowdsourced
}

study

\author{
Daniel Kondziella ${ }^{1,2}$, Markus Harboe Olsen ${ }^{3}$, Coline L. Lemale ${ }^{4,5}$, Jens P. Dreier 4,5,6,7,8
}

${ }^{1}$ Department of Neurology, Rigshospitalet, Copenhagen University Hospital, Copenhagen, Denmark

${ }^{2}$ Faculty of Health and Medical Sciences, University of Copenhagen, Copenhagen, Denmark ${ }^{3}$ Department of Neuroanesthesiology, Rigshospitalet, Copenhagen University Hospital,

2
Copenhagen, Denmark

${ }^{4}$ Department of Neurology, Charité - Universitätsmedizin Berlin, Freie Universität Berlin, Humboldt-Universität zu Berlin, Berlin Institute of Health, Berlin, Germany

${ }^{5}$ Center for Stroke Research Berlin, Charité - Universitätsmedizin Berlin, Freie Universität Berlin, Humboldt-Universität zu Berlin, Berlin Institute of Health, Berlin, Germany

${ }^{6}$ Department of Experimental Neurology, Charité - Universitätsmedizin Berlin, Freie Universität Berlin, Humboldt-Universität zu Berlin, Berlin Institute of Health, Berlin, Germany ${ }^{7}$ Bernstein Center for Computational Neuroscience Berlin, Berlin, Germany ${ }^{8}$ Einstein Center for Neurosciences Berlin, Berlin, Germany

Corresponding Author:

Daniel Kondziella ${ }^{1,2,3}$, MD, MSc, dr.philos., FEBN

Department of Neurology, Rigshospitalet, Copenhagen University Hospital 
Blegdamsvej 9

27

28

29

30

31

32

33

34
DK-2100 Copenhagen

Email address: daniel_kondziella@yahoo.com

\section{Abstract}

Background: Near-death experiences (NDE) occur with imminent death and in situations of stress and danger but are poorly understood. Evidence suggests that NDE are associated with rapid eye movement (REM) sleep intrusion, a feature of narcolepsy. Previous studies further found REM abnormalities and an increased frequency of dream-enacting behavior in migraine patients, as well as an association between migraine with aura and narcolepsy. We therefore investigated if NDE are more common in people with migraine aura.

Methods: We recruited 1037 laypeople from 35 countries and 5 continents, without any filters except for English language and age $\geq 18$ years, via a crowdsourcing platform. Reports were validated using the Greyson NDE Scale.

Results: Eighty-one of 1037 participants had NDE (7.8\%; CI 6.3-9.7\%). There were no significant associations between NDE and age ( $p>0.6$, t-test independent samples) or gender ( $p>0.9$, chisquare test). The only significant association was between NDE and migraine aura: Forty-eight (6.1\%) of 783 subjects without migraine aura and $33(13.0 \%)$ of 254 subjects with migraine aura had NDE $(p<0.001$, chi-square test, odds ratio $(\mathrm{OR})=2.29)$. In multiple logistic regression analysis, migraine aura remained significant after adjustment for age ( $\mathrm{p} \leq 0.001$, OR 2.31$)$, gender $(\mathrm{p}<0.001$, OR 2.33), or both $(\mathrm{p}<0.001$, OR 2.33).

Conclusions: In our sample, migraine aura was a predictor of NDE. This indirectly supports the association between NDE and REM intrusion and might have implications for the understanding 
51 of NDE, because a variant of spreading depolarization (SD), terminal SD, occurs in humans at the

52 end of life, while a short-lasting variant of SD is considered the pathophysiological correlate of

53 migraine aura.

54

\section{Introduction}

56

57 Near-death experiences (NDE) include emotional, self-related, spiritual and mystical perceptions

58 and feelings, occurring in situations close to death or in other situations of imminent physical or emotional danger (Greyson, 1983; Parnia et al., 2014). Common themes of NDE comprise, but are not restricted to, out-of-body experiences, visual and auditory hallucinations, distortion of time perception, and increased speed of thoughts (Greyson, 1983). See (Peinkhofer, Dreier \& Kondziella, 2019) for a recent overview on NDE.

The neuronal mechanisms of NDE are poorly understood. Nelson and colleagues previously proposed the concept that rapid eye movement (REM) sleep intrusion and REM related out-ofbody experiences could occur at the time of a life-threatening event and might explain many elements of NDE (Nelson et al., 2006; Nelson, Mattingly \& Schmitt, 2007). REM sleep is defined by rapid and random saccadic eye movements, loss of muscle tone, vivid dreaming, and cortical activation as revealed by desynchronization of the scalp electroencephalography (EEG). REM state features can intrude into wakefulness, both in healthy individuals and patients with narcolepsy. This may cause visual and auditory hallucinations at sleep onset (hypnagogic) or upon awakening (hypnopompic) and muscle atonia with sleep paralysis and cataplexy (Scammell, 2015). According to the hypothesis of Nelson and colleagues, danger provokes the arousal of neural pathways that, when stimulated, are known to generate REM-associated responses. This was interpreted as a "diathesis-stress model" (Nelson et al., 2006; Long \& Holden, 2007). In this 
75 model, an unusually sensitive arousal system (i.e. the diathesis), as evidenced by the experience of 76 REM intrusion, would predispose people to NDE in situations of stress and danger. To test their

77 hypothesis, Nelson and colleagues conducted a survey comparing a group of individuals with self78 reported NDE and an age- and sex-matched control group (Nelson et al., 2006). The results 79 suggested that episodes of REM intrusion are more common in individuals with NDE.

80 The study by Nelson et al. has been criticized (Long \& Holden, 2007), however, which recently 81 inspired us to carry out a follow-up study in a different setting to address some of the criticism 82 (Kondziella, Dreier \& Olsen, 2019). For example, Long and Holden pointed out that 40\% of the 83 people with NDE in the Nelson study denied ever having experienced an episode of REM 84 intrusion, suggesting that there may be a link between the two phenomena, but not a 1:1 85 relationship (Long \& Holden, 2007). In our crowdsourced survey, 106 of 1034 participants 86 reported NDE according to a Greyson NDE Scale (GNDES) score $\geq 7$, and $50(47 \%)$ of these 87 individuals fulfilled the criteria of REM intrusion according to almost the identical questionnaire 88 that Nelson and colleagues had used (Kondziella, Dreier \& Olsen, 2019). In contrast, only 17\% of 89 individuals without NDE reported REM intrusions. Based on multivariate regression analysis, we 90 found that REM intrusion is a predictor of NDE (Kondziella, Dreier \& Olsen, 2019). Thus, we 91 confirmed the results of Nelson and colleagues, but also the limitation that this is not a $1: 1$ 92 relationship.

93 A more central point of criticism was related to the control group in Nelson and colleagues' study 94 which consisted mainly of medical personnel, a likely selection bias (Long \& Holden, 2007). We 95 countered this in our survey with a crowdsourced approach in which the control group originated 96 from the same population as the NDE group (i.e. unprimed laypeople) (Kondziella, Dreier \& 97 Olsen, 2019). Our survey was announced under the headline "Survey on near-death experiences 
98 and (related experiences)", but we did not provide further information about the content of the 99 study. Participants were informed that their monetary reward was fixed, regardless of whether they 100 would report having had an NDE or not. Then, we asked the participants to complete a 101 questionnaire comprising demographic information, followed by the questions about REM 102 intrusion. Subsequently, participants were asked if they ever had experienced an NDE. If not, the 103 survey ended there; if yes, participants were asked in detail about this experience and information 104 about all 16 GNDES items was collected (Kondziella, Dreier \& Olsen, 2019). In this way, we think 105 that we were able to dispel the previous criticism regarding the control group.

106 Long and Holden also explained how the questionnaire for REM intrusion could be misinterpreted 107 by people with NDE, possibly leading to an overestimation of the association between REM 108 intrusion and NDE (Long \& Holden, 2007). It is indeed difficult to address this problem with a 109 questionnaire containing only closed questions. Therefore, we also gave our participants the 110 opportunity to describe their experiences in their own words (Kondziella, Dreier \& Olsen, 2019). 111 Another approach to address this problem is to investigate if comorbidities of REM intrusion, 112 which might be easier to detect with a questionnaire, are associated with NDE too. In this context, 113 it is interesting that REM sleep abnormalities have been linked to migraine. Thus, recurrent vivid 114 dreams are associated with migraine attacks (Lippman, 1954); migraine attacks often occur during 115 REM sleep (Levitan, 1984); hallucinations are not infrequent in people with migraine (Lippman, 116 1951, 1953; Daniel C \& Donnet A, 2011); migraine patients exhibit increased REM sleep and 117 prolonged REM sleep latencies (Drake et al., 1990); and they show a significantly increased 118 frequency of dream-enacting behavior (Suzuki et al., 2013). In addition, several studies found an 119 association between migraine and narcolepsy, a disorder involving REM intrusion (Dahmen et al., 120 1999, 2003; Longstreth et al., 2007; Suzuki et al., 2015; Yang et al., 2017). For example, Yang 
121 and colleagues found a consistently higher risk of developing narcolepsy in children with migraine

122 compared to those without, and this risk was particularly high in children with migraine with aura

123 (Yang et al., 2017).

124 On this basis, we hypothesized that, analogous to an unusually sensitive arousal system underlying 125 REM intrusion, an increased susceptibility of the brain to spreading depolarization (SD), the 126 assumed pathophysiological correlate of migraine aura (Figure 1A), could predispose people to 127 NDE. To test this hypothesis, we recruited a large global sample of laypersons and investigated if 128 the lifetime occurrence of migraine aura is more common in people with NDE.

129

130

131

132

133

134

135

136

137

138

139

140

141

142

143

144

145

\section{Materials \& Methods}

\section{Study design}

Our objective was to investigate whether people with a history of migraine aura are more likely to have NDE, and vice versa, than people without migraine aura. We used an online platform, Prolific Academic (https://prolific.ac/), to recruit an international sample of laypeople. Like Amazon's Mechanical Turk, Prolific Academic is a crowdsourcing online platform to recruit human subjects that can be used for research purposes (Kondziella, Dreier \& Olsen, 2019; Kondziella, Cheung \& Dutta, 2019) and that compares favorably in terms of data quality, including honesty and diversity of participants (Peer et al., 2017). Participants were recruited without any filters except for English language and age $\geq 18$ years, and we excluded participants who had been enrolled in our previous study on NDE and REM intrusion (Kondziella, Dreier \& Olsen, 2019). The study was announced under the headline "Survey on near-death experiences and headache" using the following text: "We wish to explore the frequency with which near-death experiences occur in the public. This 
146 should take no more than 1.5 minutes on average (a little bit longer, if you have had such an

147 experience, and a little bit less, if you haven't). You will be paid $0.20 \$$ after completing the survey.

148 Please note that we might use your anonymous answers when writing a paper."

149 From all participants, we collected information about age, gender, place of residence and 150 employment status (data provided automatically by Prolific Academic); if they had frequent

151 headaches; if yes, if these headaches could last longer than 4 hours and were associated with visual 152 or non-visual aura (Kaiser et al., 2019); if participants ever had an NDE; if yes, if this experience 153 occurred in a truly life-threatening situation or in a situation that just felt so; if the experience was 154 neutral, pleasant or unpleasant; and all participants with an NDE were asked to provide information 155 about all 16 items of the GNDES, the most widely used standardized tool to identify, confirm and 156 characterize NDE in research (Greyson, 1983). Like in our previous study (Kondziella, Dreier \& 157 Olsen, 2019), NDE was defined by a GNDES score $\geq 7$. We evaluated all reports of NDE, 158 irrespective of whether they occurred in truly life-threatening situations or in situations that just 159 felt so. Participants with an NDE (and those who claimed an NDE but scored 6 or less points on 160 the GNDES) were also given the opportunity to describe this in their own words (optional). We 161 did not inquire about REM sleep intrusion, which we assessed in our previous study (Kondziella, 162 Dreier \& Olsen, 2019). Table 1 provides details.

164 Statistics

165 Using a very high population size $(300,000,000)$, a confidence level of $95 \%$ and a margin of error 166 of $5 \%$, we estimated the required sample size to be 384 participants. However, since previous 167 studies have estimated the frequency with which NDE occur in the public to be 5-10\%, including 
168 our own on NDE and REM intrusion (Kondziella, Dreier \& Olsen, 2019), we decided to enroll 169 approximately 1000 participants to identify an estimated number of 100 individuals with an NDE.

170 In univariate analysis, associations between potential predictors (age, gender, migraine aura) for

171 NDE were examined using chi-square test and t-test for independent samples. Additionally, we

172 used multiple logistic regression to analyze the association between migraine aura and NDE 173 adjusted for age and gender. The level of significance was 0.05 (two-sided) for all statistical tests. 174 Statistical analysis was performed with SPSS 23.0 (IBM, Armonk, NY, USA).

175

\section{Ethics}

177 Participants gave consent for publication of their anonymous data. Participation was voluntary, 178 anonymous and restricted to those aged 18 years or older. Participants received a monetary 179 reimbursement after completing the survey, in accordance with the Prolific Academic's ethical 180 rewards principle ( $\geq \$ 6.50 / \mathrm{h}$ ). The Ethics Committee of the Capital Region of Denmark waives 181 approval for online surveys (Section 14 (1) of the Committee Act. 2; http://www.nvk.dk/english).

\section{Data Availability Statement}

184 The de-identified raw data are provided in the online supplemental files.

185

186

187

188

189

190

191

\section{Results}

We recruited 1037 laypeople from 35 countries and 5 continents (mean age: 31 years, standard deviation: 11.1 years, median age: 28 years, interquartile range (IQR): $23-36$ years; 76\% fully or part-time employed or in training), most of which were residing in Europe and North America 
192 (Figure S1, online supplemental files). Six participants identified themselves as transgender, 531

$193(52 \%)$ as female, and $500(48 \%)$ as male.

194

195 Near-death experiences: Frequency and phenomenology

196 Two-hundred-eighty-six participants (28\%; CI 95\% 25-30\%) claimed an NDE. The most frequent 197 symptoms were abnormal time perception (faster or slower than normal; reported by 257 198 participants; 90\%); extraordinary speed of thoughts $(\mathrm{n}=169 ; 59 \%)$; exceptional vivid senses $199(\mathrm{n}=165 ; 58 \%)$; and feeling separated from one's body, including out-of-body experiences $(\mathrm{n}=113$; $20040 \%$ ). Participants perceived the situation in which they made their experience slightly more often 201 as truly life-threatening $(n=165 ; 58 \%)$ than not $(n=121 ; 42 \%)$.

202 However, only 81 of 286 individuals who claimed an NDE reached the threshold of $\geq 7$ points on 203 the GNDES (28\%; CI 95\% 23-34\%). Hence, confirmed NDE were reported by 81 of 1037 204 participants (8\%; CI 95\% 6.3-9.7\%) (Figures 2 and 3). Confirmed NDE were perceived much 205 more often as pleasant $(n=29 ; 49 \%)$ than experiences that did not qualify as NDE according to the 206 GNDES ( $\mathrm{n}=21 ; 13 \% ; \mathrm{p}<0.0001$; Chi-square test; neutral experiences excluded). Table 2 provides 207 selected written reports from participants with an NDE of $\geq 7$ GNDES points and Table 3 from 208 participants with $<7$ GNDES points.

\section{Headache and migraine aura}

211 Seven-hundred-twenty of 1037 individuals (69\%) answered "yes" to the following question about 212 a primary headache disorder: "Do you get headaches that are NOT caused by a head injury, 213 hangover, or an illness such as the cold or the flu?" The male-to-female ratio of people who 214 responded "yes" to this question was 1:1.3. Two-hundred-fifty-four of 1037 individuals (24\%) 
215 fulfilled criteria (Kaiser et al., 2019) of having experienced a migraine aura at any point during 216 their lifetime. Individuals could have different types of migraine aura. Two-hundred-thirty of 254 217 (91\%) individuals reported having had visual auras, 60 (24\%) somato-sensory auras, 49 (19\%) 218 motor auras and $21(8 \%)$ aphasic/dysarthric auras. Hundred-seventy-four of 531 women (33\%) 219 had a migraine aura and 77 of 500 men (15\%). This difference was statistically significant $220(\mathrm{p}<0.001$, Chi-square test; male-to-female ratio: 1:2.2). People with migraine aura were slightly 221 older than people without migraine aura (median age: 30 (IQR: 24-38) years versus median age: 22228 (IQR: 22-36) years, p=0.005, Mann-Whitney Rank Sum Test).

223

224

Near-death experiences and evidence of migraine aura

225 There were no significant associations between confirmed NDE and age ( $\mathrm{p}>0.6$, $\mathrm{t}$-test independent 226 samples) or gender ( $>0.9$, chi-square test). The only significant association was between 227 confirmed NDE and migraine aura: Forty-eight (6.1\%) of 783 subjects without migraine aura and 228 $33(13.0 \%)$ of 254 subjects with migraine aura had experienced an NDE ( $p<0.001$, chi-square test, 229 odds ratio $=2.29$ ). In multiple logistic regression analysis with age, gender and the interaction of 230 age and gender, none of these potential predictors was significant. However, migraine aura 231 remained significant after adjustment for age $(\mathrm{p}<0.001$, odds ratio $=2.31)$, gender $(\mathrm{p}<0.001$, odds ratio $=2.33)$, and both age and gender $(\mathrm{p}<0.001$, odds ratio $=2.33)$.

233

234

235

236

237

238

239

\section{Discussion}

\section{The prevalence of $N D E$}

The prevalence of individuals with an NDE is estimated at about $4-8 \%$ in the general population (Gallup \& Proctor, 1982; Knoblauch, Schmied \& Schnettler, 2001; Perera, Padmasekara \& 
240 Belanti, 2005; Facco \& Agrillo, 2012; Chandradasa et al., 2018). In our survey, it was 8\%. We

241 found a prevalence of $10 \%$ using the same criteria in our previous crowdsourcing online survey

242 on NDE and REM intrusion (Kondziella, Dreier \& Olsen, 2019), indicating that this prevalence is

243 quite robust. Unlike most previous reports in which NDE were almost always associated with

244 peace and well-being (Thonnard et al., 2013; Charland-Verville et al., 2014; Martial et al., 2017,

245 2018; Cassol et al., 2018), we confirmed recent findings that many people find their NDE

246 unpleasant (Charland-Verville et al., 2015; Kondziella, Dreier \& Olsen, 2019; Cassol et al., 2019).

247 However, experiences with the cut-off score of $\geq 7$ GNDES points were reported more often as

248 pleasant (49\%) than experiences with a lower score (13\%).

249

250 Migraine aura is a predictor of $N D E$

251 Migraine aura was a predictor of NDE in our sample. This association was very stable. Regardless

252 of whether either no adjustment, an adjustment for age, for sex or for both was performed, the odds

253 ratios for migraine aura only varied between 2.29 and 2.33. However, a potential limitation of our

254 study is the announcement of the internet query in which we stated that we would investigate for

255 NDE and headache. This might have attracted more people with NDE and headache. The overall

256 prevalence for all types of primary headache, including tension-type headache, was $69 \%$ in our

257 survey. Tension-type headache is the most common form of headache (Jensen, 2018). Its aggregate

258 prevalence in the general population across different studies was 38\% (Jensen, 2018). Yet, in a

259 population-based study in Denmark, a much higher lifetime prevalence of $78 \%$ was found

260 (Lyngberg et al., 2005; Jensen, 2018). The high prevalence of primary headaches in our survey is

261 hence within the realm of possibility but raises the question if we have attracted a disproportionate

262 number of people with headache. This could include people with migraine with aura. The 
263 observation that $24 \%$ of the participants in our survey met criteria for a migraine aura, while 264 population-based studies have estimated this prevalence at only $4 \%$ in the general population, 265 renders this indeed likely (Russel et al., 1995). The young average age, typical of an Internet-based 266 study, could have contributed to over-representation of migraineurs with aura. The way we phrased 267 our headache questions could be another reason, as we did not intend to validate a migraine 268 diagnosis according to established criteria (Kaiser et al., 2019). Instead, we used a more inclusive 269 approach to identify people with a high likelihood of having migraine aura because we were not 270 interested in migraine per se but rather in migraine aura as a possible predictor for an NDE (Kaiser 271 et al., 2019). Since population-based studies suggest that spontaneous migraine aura is four times 272 less common in people without typical migraine headache than in people with typical migraine 273 headache (Russel et al., 1995), it is unlikely that the over-representation of people with migraine 274 aura in our survey resulted from the fact that we also included people with migraine aura without 275 typical migraine headache. However, we did not ask whether the aura symptoms lasted at least 5 276 minutes. (It should be noted that the threshold of $>5$ minutes to classify as migraine aura is 277 arbitrary). Accordingly, in humans it has been shown that SD, the pathophysiological correlate of 278 migraine aura, may occur in spatially very limited fields and that the propagation speed in the 279 cortical tissue ranges between $\sim 2$ and $9 \mathrm{~mm} / \mathrm{min}$ (Woitzik et al., 2013)). On one hand, this could 280 have contributed to the discrepancy between our data and population-based migraine studies. On 281 the other hand, the male-to-female ratio in individuals with migraine aura was 1:2.2 in our survey, 282 which is well in line with the results of population-based studies and supports that we indeed 283 detected variants of migraine aura (Russel et al., 1995). In contrast, the male-to-female ratio of a 284 primary headache disorder, be it tension-type headache, migraine or a rarer headache, was 1:1.3 
285 overall. This ratio is again well in line with the assumption that the vast majority of primary

286 headache sufferers in our survey had episodic tension-type headache (Jensen, 2018).

287 The recurrent burden of headache may have increased motivation to participate in our survey,

288 although this remains entirely speculative. The important question, however, is whether the 289 combination of NDE and migraine aura disproportionately increased the motivation of affected 290 people to join our study. Mathematically, we deal with three random factors: migraine aura 291 (yes/no), NDE (yes/no), and participation (yes/no). The two-fold dependencies between 292 participation and migraine aura or NDE appear unproblematic. In contrast, a three-fold 293 dependency between participation, migraine aura and NDE could have produced a spurious 294 association. However, we consider this unlikely because, for instance, the entire survey was 295 finished during such a short time frame (i.e. within 3 hours after posting the survey online) that 296 word-of-mouth communication of the survey's topic seems very unlikely.

297 Internet-based surveys and more traditional mail-based questionnaires or laboratory-based studies 298 each have their advantages and disadvantages (Kaiser et al., 2019). We suggest that a combination 299 of the different approaches is more meaningful than using just one method (Kondziella, Dreier \& 300 Olsen, 2019). On one side, complex clinical and ethical concepts cannot be fully captured by an 301 online survey (Woods et al., 2015; Peer et al., 2017). For instance, we did not inquire about 302 precipitating factors/contexts in which participants had experienced their NDE (although we did 303 so in our previous study on NDE and REM intrusion (Kondziella, Dreier \& Olsen, 2019)). Future 304 non-internet-based studies will therefore be necessary to verify that NDE and migraine aura are 305 indeed associated. On the other side, the anonymous character of a crowdsourcing online survey 306 decreases the influence of psychological bias (Woods et al., 2015; Peer et al., 2017), because there 307 is no incentive to satisfy the investigator by exaggerating or inventing memories. There was no 
308 monetary incentive in our survey either, since we instructed participants that their reimbursement

309 would be the same regardless of whether they reported an NDE or headache or not. In addition,

310 we recruited a much larger sample than would have been feasible during a conventional survey.

311 Although participants from Europe and North America made up the largest share, ours was indeed

312 a global sample with people from 35 countries and 5 continents.

313

314 NDE and the neurobiology of dying

315 In the largest prospective multi-center observational trial on AWAreness during Resuscitation 316 (AWARE), 46\% of 140 survivors reported memories following their cardiac arrest with seven 317 major cognitive themes (Parnia et al., 2014). Nine percent of the survivors met the criteria for an 318 NDE according to the GNDES. Two percent described awareness with explicit memories of 319 'seeing' or 'hearing' real events related to their resuscitation. Importantly, one patient had a 320 verifiable period of conscious awareness during which time cerebral function was not expected 321 (Parnia et al., 2014). Although speculative, it seems likely that there is a neurobiological basis for 322 this observation (Nelson et al., 2006; Parnia et al., 2014; Martial et al., 2019; Peinkhofer, Dreier $323 \&$ Kondziella, 2019). The pathophysiological events that occur during the process of dying are of 324 obvious interest in this regard (Vrselja et al., 2019). The transition from life to death is thus 325 characterized by four major events: loss of circulation, loss of respiration, loss of spontaneous 326 electrocorticography (ECoG) activity, and a terminal SD without repolarization. These four events 327 occur always, but not necessarily in the same order (Dreier et al., 2018, 2019; Carlson et al., 2018).

328 In the most common scenario, arrest of systemic circulation, respiration and ECoG activity 329 develops more or less simultaneously, while terminal SD follows the complete arrest of ECoG 330 activity with a latency of 13 to 266 seconds (Dreier et al., 2018). Along this sequence, the 
331 invasively recorded direct current (DC)/alternate (AC)-ECoG activity can be roughly divided into

332 four different phases which are illustrated with an original recording from a previous study (Dreier

333 et al., 2018) in Figure 1B: In phase 1, spontaneous ECoG activity is still measurable; phase 2 is

334 characterized by a complete loss of ECoG activity starting simultaneously in different cortical

335 regions and layers, which is referred to as non-spreading depression of spontaneous activity

336 (Dreier, 2011); in phase 3, the terminal SD starts but, from a phenomenologically point of view,

337 is initially similar to SD spreading in healthy grey brain matter (Figure 1A) (Dreier \& Reiffurth,

338 2015; Hartings et al., 2017a); and finally, in phase 4 a negative ultraslow potential signals the

339 second phase of terminal SD (Oliveira-Ferreira et al., 2010; Hartings et al., 2017b; Dreier et al.,

340 2018, 2019; Lückl et al., 2018; Carlson et al., 2018).

341 The pertinent question arising from the AWARE study is whether phase 2 and (the transition to)

342 phase 3 are compatible with a conscious perception by the patient - and hence, might contribute to

343 the pathophysiological mechanisms of an NDE. On closer examination of the experimental data,

344 it is interesting that the non-spreading depression of spontaneous ECoG activity in phase 2 does

345 not result from a loss of synaptic activity, but on the contrary from vesicular release of various

346 transmitters, including GABA and glutamate, leading to an incoherent, massive increase in

347 miniature excitatory and inhibitory postsynaptic potentials that replace the normal postsynaptic

348 potentials (Fleidervish et al., 2001; Allen, Rossi \& Attwell, 2004; Revah et al., 2016). This

349 probably leads to gradual depletion of the releasable pool of vesicles in the synaptic terminals, and

350 thereby significantly distorts neuronal interactions (Fleidervish et al., 2001; Revah et al., 2016).

351 (Not only are the miniature potentials small, but the abnormal neuronal desynchronization also

352 prevents these potentials from summing-up, which precludes their measurement using

353 comparatively insensitive methods such as subdural and intracortical ECoG or the even cruder 
354 scalp EEG.) Initially, neurons are hyperpolarized (Tanaka et al., 1997; Müller \& Somjen, 2000).

355 Over time, intracellular calcium and extracellular potassium concentrations gradually increase, 356 while extracellular pH decreases (Kraig, Ferreira-Filho \& Nicholson, 1983; Mutch \& Hansen, 357 1984; Nedergaard \& Hansen, 1993; Erdemli, Xu \& Krnjevic, 1998; Müller \& Somjen, 2000; 358 Dreier et al., 2002). Eventually, hyperpolarization turns into neuronal depolarization. When the 359 adenosine triphosphate (ATP) stores are exhausted, ATP-dependent membrane pumps such as the $360 \mathrm{Na}, \mathrm{K}-\mathrm{ATPase}$ become unable to replenish the leaking ions. Consequently, SD erupts at one or more sites of the cortical tissue and spreads into the environment as a giant wave of depolarization.

362 It is important to understand that this terminal SD marks the onset of the toxic cellular changes 363 that ultimately lead to death, but it is not a marker of death per se, since the SD is reversible - to 364 a certain point - with restoration of the circulation (Hossmann \& Sato, 1970; Heiss \& Rosner, 365 1983; Memezawa, Smith \& Siesjö, 1992; Ayad, Verity \& Rubinstein, 1994; Shen et al., 2005; 366 Pignataro, Simon \& Boison, 2007; Nozari et al., 2010; Lückl et al., 2018). Thus, in contrast to 367 what happens during coma or sedation, when the brain dies, it undergoes a massive and 368 unstoppable depolarization process (and hence, a very last state of "activation") (Dreier, 2011).

369 Returning to the association between NDE and REM intrusion, it would be interesting to know if 370 also a link exists between miniature excitatory/inhibitory postsynaptic potentials and REM sleep.

371 Information is scarce, but there is indeed evidence that these potentials occur in the healthy brain 372 and are involved in the sleep-wake cycle and both REM and non-REM sleep (Yang \& Brown, 373 2014; Christensen et al., 2014; Sangare et al., 2016). Yet, the connection between these potentials

374 in healthy people, on one hand, and disordered neuronal processing, including NDE, on the other 375 hand, has never been properly investigated. 
376 Another unsolved question is if terminal SD could produce bright light phenomena and tunnel

377 vision similar to what happens during a migraine aura, when SD spread through healthy cortical

378 tissue. In this context, it is particularly thought-provoking that terminal SD is not always the final

379 event, but data from so far 3 patients indicate that terminal SD can sometimes indeed precede 380 circulatory arrest and initiate a spreading depression of spontaneous activity like that in 381 migraineurs with aura (Figure 1C) (Dreier et al., 2018, 2019; Carlson et al., 2018). In contrast to 382 migraine aura, activity then remains depressed at the time of cardiac death.

383 It is important to bear in mind that virtually all humans (and all animals, including insects (Spong,

384 Dreier \& Robertson, 2017)) undergo terminal SD at the end of their life, whereas only a minority 385 of people have a migraine aura during their lifetime. Hence, although terminal SD may play a role 386 in the development of NDE, migraine aura during lifetime is probably not required for having an 387 NDE with a bright light at the end of life. However, people with a propensity for migraine aura 388 may be more likely to experience terminal SD while the brain is still electrically active (Figure 389 1C). Thus, if terminal SD facilitates NDE, this would suggest that the event of a terminal SD can 390 still be perceived and remembered.

391 To substantiate or dismiss these speculations, it would be necessary to fully understand how the 392 changing polarization states of approximately 20 billion neurons in the neocortex (Mortensen et 393 al., 2014) create the conscious awareness of an individual, an area of intense but unsolved research 394 (Owen et al., 2006; Giacino et al., 2014; Kondziella et al., 2016; Paulson et al., 2017; Demertzi et 395 al., 2019). This seems important because of the increasing practice of organ donation after cardio396 circulatory death (DCD). In countries where DCD is practiced, physicians have reached consensus 397 that death should occur somewhere between a few seconds and 10 minutes after loss of circulatory 398 function (Boucek et al., 2008; Stiegler et al., 2012; Dhanani et al., 2012; van Veen et al., 2018). 
399 Thus, a survey on postmortem organ donation in the framework of the CENTER-TBI study 400 recently revealed that as many as 10 out of 64 centers (16\%) in Europe and Israel immediately 401 begin organ retrieval from the donor after a "flat line electrocardiogram" is detected on the monitor 402 (van Veen et al., 2018). Critical voices have been raised, however (Rady \& Verheijde, 2016; 403 Youngner \& Hyun, 2019). Due to the above-mentioned uncertainties in our understanding of the 404 dying process, we think it is indeed prudent to consider if organ removal should first be permitted 405 when the neurons in the donor's brain no longer exhibit synaptic transmission and alterations of 406 their polarization state. In other words, organ harvesting should perhaps be postponed until the 407 donor's entire brain has unmistakably reached the negative ultraslow potential phase of terminal 408 SD. It follows that a better understanding of NDE may be relevant to protect the interests of 409 potential organ donors in the context of DCD.

412 Conclusions and future directions

414 In a large global sample of unprimed laypeople, migraine aura was significantly associated with 415 NDE, even after multivariate adjustment. The connection between migraine aura, REM intrusion 416 and NDE is complex. For instance, the brainstem plays an important role in REM intrusion, and 417 dream-like hallucinations such as those in REM sleep are known from people with lesions near 418 the meso-pontine paramedian reticular formation and the midbrain cerebral peduncles (i.e. 419 peduncular hallucinations) (Galetta \& Prasad, 2017), suggesting that dysfunction of the REM420 inhibiting serotonergic dorsal raphe nuclei and the noradrenergic locus coeruleus facilitates REM 421 intrusion (Hobson, McCarley \& Wyzinski, 1975; Manford \& Andermann, 1998; Kayama \& 422 Koyama, 2003; de Lecea, Carter \& Adamantidis, 2012). A large body of evidence further indicates 423 that the brainstem also plays an important role in the pathogenesis of migraine (Akerman, Holland 
424 \& Goadsby, 2011). Moreover, REM sleep abnormalities have been described in migraineurs; and

425 several reports have substantiated the notion that migraine, in particular migraine with aura, is 426 associated with narcolepsy (Lippman, 1951; Levitan, 1984; Drake et al., 1990; Dahmen et al., 427 1999, 2003; Longstreth et al., 2007; Suzuki et al., 2013, 2015; Yang et al., 2017) and hallucinations

428 (Lippman, 1951, 1953; Daniel C \& Donnet A, 2011). Hence, although a propensity for REM 429 intrusion is neither necessary, nor sufficient, for having NDE (Britton \& Bootzin, 2004; Lopez et 430 al., 2006; Long \& Holden, 2007), we and others have suggested that REM intrusion is a predictor 431 of NDE (Nelson et al., 2006; Kondziella, Dreier \& Olsen, 2019). In the present study we found 432 that migraine aura is also a predictor of NDE. The relationship between NDE and migraine aura 433 raises many novel questions which deserve further investigations. In the broadest sense, 434 excitation/inhibition imbalance across different brain structures is likely to play a role (van den 435 Maagdenberg et al., 2004; Tottene et al., 2009; Ambrosini et al., 2016). However, migraine aura 436 also has an important vascular component that is particularly interesting for the study of NDE and 437 the dying brain and further increases the complexity of these phenomena and their interactions 438 (van den Maagdenberg et al., 2004; Tottene et al., 2009; Dreier \& Reiffurth, 2015).

439

440

\section{1}

442

443

444

445

446

447

448

449

450

451

452

\section{Acknowledgements}

N/A.

\section{References}

Akerman S., Holland PR., Goadsby PJ. 2011. Diencephalic and brainstem mechanisms in migraine. Nature Reviews Neuroscience 12:570-584. DOI: 10.1038/nrn3057.

Allen NJ., Rossi DJ., Attwell D. 2004. Sequential release of GABA by exocytosis and reversed uptake leads to neuronal swelling in simulated ischemia of hippocampal slices. The Journal of Neuroscience: the official journal of the Society for Neuroscience 24:3837-49. DOI: 10.1523/JNEUROSCI.5539-03.2004.

Ambrosini A., Iezzi E., Perrotta A., Kisialiou A., Nardella A., Berardelli A., Pierelli F., 
453

454

455

456

457

458

459

460

461

462

463

464

465

466

467

468

469

470

471

472

473

474

475

476

477

478

479

480

481

482

483

484

485

486

487

488

489

490

491

492

493

494

495

496

497

498

Schoenen J. 2016. Correlation between habituation of visual-evoked potentials and magnetophosphene thresholds in migraine: A case-control study. Cephalalgia : an international journal of headache 36:258-64. DOI: 10.1177/0333102415590241.

Ayad M., Verity MA., Rubinstein EH. 1994. Lidocaine delays cortical ischemic depolarization: relationship to electrophysiologic recovery and neuropathology. Journal of Neurosurgical Anesthesiology 6:98-110.

Boucek MM., Mashburn C., Dunn SM., Frizell R., Edwards L., Pietra B., Campbell D., Denver Children's Pediatric Heart Transplant Team. 2008. Pediatric heart transplantation after declaration of cardiocirculatory death. The New England Journal of Medicine 359:709-14. DOI: 10.1056/NEJMoa0800660.

Britton WB., Bootzin RR. 2004. Near-death experiences and the temporal lobe. Psychological Science 15:254-258. DOI: 10.1111/j.0956-7976.2004.00661.x.

Carlson AP., Shuttleworth CW., Major S., Lemale CL., Dreier JP., Hartings JA. 2018. Terminal spreading depolarizations causing electrocortical silencing prior to clinical brain death: case report. Journal of Neurosurgery:1-7. DOI: 10.3171/2018.7.JNS181478.

Cassol H., Martial C., Annen J., Martens G., Charland-Verville V., Majerus S., Laureys S. 2019. A systematic analysis of distressing near-death experience accounts. Memory (Hove, England):1-8. DOI: 10.1080/09658211.2019.1626438.

Cassol H., Pétré B., Degrange S., Martial C., Charland-Verville V., Lallier F., Bragard I., Guillaume M., Laureys S. 2018. Qualitative thematic analysis of the phenomenology of near-death experiences. PLOS ONE 13:e0193001. DOI: 10.1371/journal.pone.0193001.

Chandradasa M., Wijesinghe C., Kuruppuarachchi KALA., Perera M. 2018. Near-Death Experiences in a Multi-religious Hospital Population in Sri Lanka. Journal of Religion and Health 57:1599-1605. DOI: 10.1007/s10943-017-0442-9.

Charland-Verville V., Jourdan J-P., Thonnard M., Ledoux D., Donneau A-F., Quertemont E., Laureys S. 2014. Near-death experiences in non-life-threatening events and coma of different etiologies. Frontiers in Human Neuroscience 8:203. DOI: 10.3389/fnhum.2014.00203.

Charland-Verville V., Lugo Z., Jourdan J-P., Donneau A-F., Laureys S. 2015. Near-Death Experiences in patients with locked-in syndrome: Not always a blissful journey. Consciousness and Cognition 34:28-32. DOI: 10.1016/j.concog.2015.03.011.

Christensen MH., Ishibashi M., Nielsen ML., Leonard CS., Kohlmeier KA. 2014. Age-related changes in nicotine response of cholinergic and non-cholinergic laterodorsal tegmental neurons: implications for the heightened adolescent susceptibility to nicotine addiction. Neuropharmacology 85:263-83. DOI: 10.1016/j.neuropharm.2014.05.010.

Dahmen N., Kasten M., Wieczorek S., Gencik M., Epplen JT., Ullrich B. 2003. Increased frequency of migraine in narcoleptic patients: a confirmatory study. Cephalalgia : an international journal of headache 23:14-9. DOI: 10.1046/j.1468-2982.2003.00343.x.

Dahmen N., Querings K., Grün B., Bierbrauer J. 1999. Increased frequency of migraine in narcoleptic patients. Neurology 52:1291-3. DOI: 10.1212/wnl.52.6.1291.

Daniel C., Donnet A. 2011. Migrainous complex hallucinations in a 17-year-old adolescent. Headache: The Journal of Head and Face Pain 51.

Demertzi A., Tagliazucchi E., Dehaene S., Deco G., Barttfeld P., Raimondo F., Martial C., Fernández-Espejo D., Rohaut B., Voss HU., Schiff ND., Owen AM., Laureys S., Naccache L., Sitt JD. 2019. Human consciousness is supported by dynamic complex patterns of brain signal coordination. Science Advances 5:eaat7603. DOI: 10.1126/sciadv.aat7603. 
499 Dhanani S., Hornby L., Ward R., Shemie S. 2012. Variability in the determination of death after

500

501

502

503

504

505

506

507

508

509

510

511

512

513

514

515

516

517

518

519

520

521

522

523

524

525

526

527

528

529

530

531

532

533

534

535

536

537

538

539

540

541

542

543

544 cardiac arrest. Journal of Intensive Care Medicine 27:238-252. DOI: $10.1177 / 0885066610396993$.

Drake ME., Pakalnis A., Andrews JM., Bogner JE. 1990. Nocturnal sleep recording with cassette EEG in chronic headaches. Headache 30:600-3.

Dreier JP. 2011. The role of spreading depression, spreading depolarization and spreading ischemia in neurological disease. Nature Medicine 17:439-447. DOI: 10.1038/nm.2333.

Dreier JP., Kleeberg J., Petzold G., Priller J., Windmüller O., Orzechowski H-D., Lindauer U., Heinemann U., Einhäupl KM., Dirnagl U. 2002. Endothelin-1 potently induces Leão's cortical spreading depression in vivo in the rat: a model for an endothelial trigger of migrainous aura? Brain : a journal of neurology 125:102-12. DOI: 10.1093/brain/awf007.

Dreier JP., Major S., Foreman B., Winkler MKL., Kang E-J., Milakara D., Lemale CL., DiNapoli V., Hinzman JM., Woitzik J., Andaluz N., Carlson A., Hartings JA. 2018. Terminal spreading depolarization and electrical silence in death of human cerebral cortex. Annals of Neurology 83:295-310. DOI: 10.1002/ana.25147.

Dreier JP., Major S., Lemale CL., Kola V., Reiffurth C., Schoknecht K., Hecht N., Hartings JA., Woitzik J. 2019. Correlates of spreading depolarization, spreading depression, and negative ultraslow potential in epidural versus subdural electrocorticography. Frontiers in Neuroscience 13:373. DOI: 10.3389/fnins.2019.00373.

Dreier JP., Reiffurth C. 2015. The stroke-migraine depolarization continuum. Neuron 86:902922. DOI: 10.1016/j.neuron.2015.04.004.

Erdemli G., Xu YZ., Krnjevic K. 1998. Potassium conductance causing hyperpolarization of CA1 hippocampal neurons during hypoxia. Journal of Neurophysiology 80:2378-2390. DOI: $10.1152 /$ jn.1998.80.5.2378.

Facco E., Agrillo C. 2012. Near-death experiences between science and prejudice. Frontiers in Human Neuroscience 6:209. DOI: 10.3389/fnhum.2012.00209.

Fleidervish IA., Gebhardt C., Astman N., Gutnick MJ., Heinemann U. 2001. Enhanced spontaneous transmitter release is the earliest consequence of neocortical hypoxia that can explain the disruption of normal circuit function. The Journal of Neuroscience : the official journal of the Society for Neuroscience 21:4600-8.

Galetta KM., Prasad S. 2017. Historical trends in the diagnosis of peduncular hallucinosis. Journal of Neuro-Ophthalmology 38:1. DOI: 10.1097/WNO.0000000000000599.

Gallup G., Proctor W. 1982. Adventures in immortality: A look beyond the threshold of death. New York, NY: McGraw-Hill.

Giacino JT., Fins JJ., Laureys S., Schiff ND. 2014. Bain injury: the state of the science. Nature Reviews Neurology 10:99-114. DOI: 10.1038/nrneurol.2013.279.

Greyson B. 1983. The near-death experience scale. Construction, reliability, and validity. The Journal of Nervous and Mental Disease 171:369-75.

Hartings JA., Shuttleworth CW., Kirov SA., Ayata C., Hinzman JM., Foreman B., Andrew RD., Boutelle MG., Brennan KC., Carlson AP., Dahlem MA., Drenckhahn C., Dohmen C., Fabricius M., Farkas E., Feuerstein D., Graf R., Helbok R., Lauritzen M., Major S., Oliveira-Ferreira AI., Richter F., Rosenthal ES., Sakowitz OW., Sánchez-Porras R., Santos E., Schöll M., Strong AJ., Urbach A., Westover MB., Winkler MK., Witte OW., Woitzik J., Dreier JP. 2017a. The continuum of spreading depolarizations in acute cortical lesion development: Examining Leão's legacy. Journal of Cerebral Blood Flow and Metabolism : official journal of the International Society of Cerebral Blood Flow and Metabolism 
545

546

547

548

549

550

551

552

553

554

555

556

557

558

559

560

561

562

563

564

565

566

567

568

569

570

571

572

573

574

575

576

577

578

579

580

581

582

583

584

585

586

587

588

589

590

37:1571-1594. DOI: 10.1177/0271678X16654495.

Hartings JA., York J., Carroll CP., Hinzman JM., Mahoney E., Krueger B., Winkler MKL., Major S., Horst V., Jahnke P., Woitzik J., Kola V., Du Y., Hagen M., Jiang J., Dreier JP. 2017b. Subarachnoid blood acutely induces spreading depolarizations and early cortical infarction. Brain : a journal of neurology 140:2673-2690. DOI: 10.1093/brain/awx214.

Heiss WD., Rosner G. 1983. Functional recovery of cortical neurons as related to degree and duration of ischemia. Annals of Neurology 14:294-301. DOI: 10.1002/ana.410140307.

Hobson JA., McCarley RW., Wyzinski PW. 1975. Sleep cycle oscillation: reciprocal discharge by two brainstem neuronal groups. Science (New York, N.Y.) 189:55-8.

Hossmann K-A., Sato K. 1970. Recovery of neuronal function after prolonged cerebral ischemia. Science 168:375-376. DOI: 10.1126/science.168.3929.375.

Jensen RH. 2018. Tension-type headache - The normal and most prevalent headache. Headache: The Journal of Head and Face Pain 58:339-345. DOI: 10.1111/head.13067.

Kaiser EA., Igdalova A., Aguirre GK., Cucchiara B. 2019. A web-based, branching logic questionnaire for the automated classification of migraine. Cephalalgia : an international journal of headache:333102419847749. DOI: 10.1177/0333102419847749.

Kayama Y., Koyama Y. 2003. Control of sleep and wakefulness by brainstem monoaminergic and cholinergic neurons. Acta Neurochirurgica. Supplement 87:3-6.

Knoblauch H., Schmied I., Schnettler B. 2001. Different kinds of near-death experience: A report on a survey of near-death experiences in Germany. Journal of Near-Death Studies 20:15-29.

Kondziella D., Cheung MC., Dutta A. 2019. Public perception of the vegetative state/unresponsive wakefulness syndrome: a crowdsourced study. PeerJ 7:e6575. DOI: $10.7717 /$ peerj.6575.

Kondziella D., Dreier JP., Olsen MH. 2019. Prevalence of near-death experiences in people with and without REM sleep intrusion. PeerJ 7:e7585.

Kondziella D., Friberg CK., Frokjaer VG., Fabricius M., Møller K. 2016. Preserved consciousness in vegetative and minimal conscious states: systematic review and metaanalysis. Journal of Neurology, Neurosurgery \& Psychiatry 87:485-92. DOI: 10.1136/jnnp2015-310958.

Kraig RP., Ferreira-Filho CR., Nicholson C. 1983. Alkaline and acid transients in cerebellar microenvironment. Journal of Neurophysiology 49:831-50. DOI: 10.1152/jn.1983.49.3.831.

de Lecea L., Carter ME., Adamantidis A. 2012. Shining Light on Wakefulness and Arousal. Biological Psychiatry 71:1046-1052. DOI: 10.1016/j.biopsych.2012.01.032.

Levitan H. 1984. Dreams which culminate in migraine headaches. Pschyotherapy and Psychosomatics 41.

Lippman C. 1951. Hallucinations in migraine. American Journal of Psychiatry 107.

Lippman C. 1953. Hallucinations of physical duality in migraine. Journal of Nervous and Mental Disease 117.

Lippman C. 1954. Recurrent dreams in migraine: an aid to diagnosis. Journal of Nervous and Mental Disease 120:273-276.

Long J., Holden J. 2007. Does the arousal system contribute to near-death and out-of-body experiences? A summary and response. Journal of Near-Death Studies 25:135-169.

Longstreth WT., Koepsell TD., Ton TG., Hendrickson AF., van Belle G. 2007. The epidemiology of narcolepsy. Sleep 30:13-26. DOI: 10.1093/sleep/30.1.13.

Lopez U., Forster A., Annoni J-M., Habre W., Iselin-Chaves IA. 2006. Near-death experience in

Peer] reviewing PDF | (2019:09:40965:1:1:NEW 26 Oct 2019) 
591

592

593

594

595

596

597

598

599

600

601

602

603

604

605

606

607

608

609

610

611

612

613

614

615

616

617

618

619

620

621

622

623

624

625

626

627

628

629

630

631

632

633

634

635

636

a boy undergoing uneventful elective surgery under general anesthesia. Pediatric Anesthesia 16:85-88. DOI: 10.1111/j.1460-9592.2005.01607.x.

Lückl J., Lemale CL., Kola V., Horst V., Khojasteh U., Oliveira-Ferreira AI., Major S., Winkler MKL., Kang E-J., Schoknecht K., Martus P., Hartings JA., Woitzik J., Dreier JP. 2018. The negative ultraslow potential, electrophysiological correlate of infarction in the human cortex. Brain : a journal of neurology 141:1734-1752. DOI: 10.1093/brain/awy102.

Lyngberg AC., Rasmussen BK., Jørgensen T., Jensen R. 2005. Has the prevalence of migraine and tension-type headache changed over a 12-year period? A Danish population survey. European Journal of Epidemiology 20:243-9.

van den Maagdenberg AMJM., Pietrobon D., Pizzorusso T., Kaja S., Broos LAM., Cesetti T., van de Ven RCG., Tottene A., van der Kaa J., Plomp JJ., Frants RR., Ferrari MD. 2004. A Cacnala knockin migraine mouse model with increased susceptibility to cortical spreading depression. Neuron 41:701-10.

Manford M., Andermann F. 1998. Complex visual hallucinations. Clinical and neurobiological insights. Brain : a journal of neurology 121 ( Pt 10):1819-40.

Martial C., Cassol H., Antonopoulos G., Charlier T., Heros J., Donneau A-F., Charland-Verville V., Laureys S. 2017. Temporality of features in near-death experience narratives. Frontiers in Human Neuroscience 11:311. DOI: 10.3389/fnhum.2017.00311.

Martial C., Cassol H., Charland-Verville V., Merckelbach H., Laureys S. 2018. Fantasy proneness correlates with the intensity of near-death experience. Frontiers in Psychiatry 9:190. DOI: 10.3389/fpsyt.2018.00190.

Martial C., Cassol HH., Charland-verville V., Pallavicini C., Sanz C., Zamberlan FF., Martínez R., Martinez Vivo R., Erowid F., Erowid E., Laureys S., Greyson B., Tagliazucchi E. 2019. Neurochemical models of near-death experiences: a large-scale study based on the semantic similarity of written reports. Consciousness and cognition 69:52-69. DOI: 10.1016/j.concog.2019.01.011.

Memezawa H., Smith ML., Siesjö BK. 1992. Penumbral tissues salvaged by reperfusion following middle cerebral artery occlusion in rats. Stroke 23:552-559. DOI: 10.1161/01.STR.23.4.552.

Mortensen HS., Pakkenberg B., Dam M., Dietz R., Sonne C., Mikkelsen B., Eriksen N. 2014. Quantitative relationships in delphinid neocortex. Frontiers in Neuroanatomy 8. DOI: 10.3389/fnana.2014.00132.

Müller M., Somjen GG. 2000. $\mathrm{Na}(+)$ and $\mathrm{K}(+)$ concentrations, extra- and intracellular voltages, and the effect of TTX in hypoxic rat hippocampal slices. Journal of Neurophysiology 83:735-45. DOI: 10.1152/jn.2000.83.2.735.

Mutch WA., Hansen AJ. 1984. Extracellular pH changes during spreading depression and cerebral ischemia: mechanisms of brain $\mathrm{pH}$ regulation. Journal of Cerebral Blood Flow \& Metabolism 4:17-27. DOI: 10.1038/jcbfm.1984.3.

Nedergaard M., Hansen AJ. 1993. Characterization of cortical depolarizations evoked in focal cerebral ischemia. Journal of Cerebral Blood Flow \& Metabolism 13:568-74. DOI: 10.1038/jcbfm.1993.74.

Nelson KR., Mattingly M., Lee SA., Schmitt FA. 2006. Does the arousal system contribute to near death experience? Neurology 66:1003-1009. DOI: 10.1212/01.wnl.0000204296.15607.37.

Nelson KR., Mattingly M., Schmitt FA. 2007. Out-of-body experience and arousal. Neurology 68:794-5. DOI: 10.1212/01.wnl.0000256784.85952.6f. 
637 Nozari A., Dilekoz E., Sukhotinsky I., Stein T., Eikermann-Haerter K., Liu C., Wang Y., Frosch

638 MP., Waeber C., Ayata C., Moskowitz MA. 2010. Microemboli may link spreading

639 depression, migraine aura, and patent foramen ovale. Annals of Neurology 67:221-229.

640 DOI: 10.1002/ana.21871.

641 Oliveira-Ferreira AI., Milakara D., Alam M., Jorks D., Major S., Hartings JA., Lück1 J., Martus

642

643

644

645

646

647

648

649

650

651

652

653

654

655

656

657

658

659

660

661

662

663

664

665

666

667

668

669

670

671

672

673

674

675

676

677

678

679

680

681

682

Experimental and preliminary clinical evidence of an ischemic zone with prolonged negative DC shifts surrounded by a normally perfused tissue belt with persistent electrocorticographic depression. Journal of Cerebral Blood Flow \& Metabolism 30:150419. DOI: $10.1038 / \mathrm{jcbfm} .2010 .40$.

Owen AM., Coleman MR., Boly M., Davis MH., Laureys S., Pickard JD. 2006. Detecting awareness in the vegetative state. Science (New York, N.Y.) 313:1402. DOI: $10.1126 /$ science. 1130197.

Parnia S., Spearpoint K., de Vos G., Fenwick P., Goldberg D., Yang J., Zhu J., Baker K., Killingback H., McLean P., Wood M., Zafari AM., Dickert N., Beisteiner R., Sterz F., Berger M., Warlow C., Bullock S., Lovett S., McPara RMS., Marti-Navarette S., Cushing P., Wills P., Harris K., Sutton J., Walmsley A., Deakin CD., Little P., Farber M., Greyson B., Schoenfeld ER. 2014. AWARE-AWAreness during REsuscitation-a prospective study. Resuscitation 85:1799-1805. DOI: 10.1016/j.resuscitation.2014.09.004.

Paulson S., Berlin HA., Ginot E., Makari G. 2017. Delving within: the new science of the unconscious. Annals of the New York Academy of Sciences 1406:12-27. DOI: 10.1111/nyas. 13390 .

Peer E., Brandimarte L., Samat S., Acquisti A. 2017. Beyond the Turk: Alternative platforms for crowdsourcing behavioral research. Journal of Experimental Social Psychology 70:153163. DOI: 10.1016/j.jesp.2017.01.006.

Peinkhofer C., Dreier J., Kondziella D. 2019. Semiology and mechanisms of near-death experiences. Current Neurology and Neuroscience Reports 19:9(62) doi: 10.1007/s11910019-0983-2.

Perera M., Padmasekara G., Belanti J. 2005. Prevalence of near-death experiences in Australia. Journal of Near-Death Studies 24:109-116.

Pignataro G., Simon RP., Boison D. 2007. Transgenic overexpression of adenosine kinase aggravates cell death in ischemia. Journal of Cerebral Blood Flow \& Metabolism 27:1-5. DOI: $10.1038 /$ sj.jcbfm.9600334.

Rady MY., Verheijde JL. 2016. Neuroscience and awareness in the dying human brain: Implications for organ donation practices. Journal of Critical Care 34:121-3. DOI: 10.1016/j.jcrc.2016.04.016.

Revah O., Lasser-Katz E., Fleidervish IA., Gutnick MJ. 2016. The earliest neuronal responses to hypoxia in the neocortical circuit are glutamate-dependent. Neurobiology of Disease 95:158-67. DOI: 10.1016/j.nbd.2016.07.019.

Russel M., Rasmussen B., Thorvaldsen P., Olesen J. 1995. Prevalence and sex-ratio of the subtypes of migraine. International Journal of Epidemiology 24:612-618. DOI: 10.1093/ije/24.3.612.

Sangare A., Dubourget R., Geoffroy H., Gallopin T., Rancillac A. 2016. Serotonin differentially modulates excitatory and inhibitory synaptic inputs to putative sleep-promoting neurons of the ventrolateral preoptic nucleus. Neuropharmacology 109:29-40. DOI: 10.1016/j.neuropharm.2016.05.015. 
683 Scammell TE. 2015. Narcolepsy. New England Journal of Medicine 373:2654-2662. DOI:

684

685

686

687

688

689

690

691

692

693

694

695

696

697

698

699

700

701

702

703

704

705

706

707

708

709

710

711

712

713

714

715

716

717

718

719

720

721

722

723

724

725

726

727

728 10.1056/NEJMra1500587.

Shen Q., Ren H., Cheng H., Fisher M., Duong TQ. 2005. Functional, perfusion and diffusion MRI of acute focal ischemic brain injury. Journal of Cerebral Blood Flow \& Metabolism 25:1265-1279. DOI: 10.1038/sj.jcbfm.9600132.

Spong KE., Dreier JP., Robertson RM. 2017. A new direction for spreading depolarization: Investigation in the fly brain. Channels (Austin, Tex.) 11:97-98. DOI: 10.1080/19336950.2016.1239898.

Stiegler P., Sereinigg M., Puntschart A., Seifert-Held T., Zmugg G., Wiederstein-Grasser I., Marte W., Meinitzer A., Stojakovic T., Zink M., Stadlbauer V., Tscheliessnigg K. 2012. A 10 min "no-touch" time - is it enough in DCD? A DCD animal study. Transplant International : official journal of the European Society for Organ Transplantation 25:48192. DOI: $10.1111 / \mathrm{j} .1432-2277.2012 .01437 . x$.

Suzuki K., Miyamoto M., Miyamoto T., Inoue Y., Matsui K., Nishida S., Hayashida K., Usui A., Ueki Y., Nakamura M., Murata M., Numao A., Watanabe Y., Suzuki S., Hirata K. 2015. The prevalence and characteristics of primary headache and dream-enacting behaviour in Japanese patients with narcolepsy or idiopathic hypersomnia: A multi-centre cross-sectional study. PLOS ONE 10:e139229. DOI: 10.1371/journal.pone.0139229.

Suzuki K., Miyamoto T., Miyamoto M., Suzuki S., Watanabe Y., Takashima R., Hirata K. 2013. Dream-enacting behaviour is associated with impaired sleep and severe headache-related disability in migraine patients. Cephalalgia 33:868-878. DOI: 10.1177/0333102413477742.

Tanaka E., Yamamoto S., Kudo Y., Mihara S., Higashi H. 1997. Mechanisms underlying the rapid depolarization produced by deprivation of oxygen and glucose in rat hippocampal CA1 neurons in vitro. Journal of Neurophysiology 78:891-902. DOI:

10.1152/jn.1997.78.2.891.

Thonnard M., Charland-Verville V., Brédart S., Dehon H., Ledoux D., Laureys S., Vanhaudenhuyse A. 2013. Characteristics of near-death experiences memories as compared to real and imagined events memories. PLOS ONE 8:e57620. DOI:

10.1371/journal.pone.0057620.

Tottene A., Conti R., Fabbro A., Vecchia D., Shapovalova M., Santello M., van den Maagdenberg AMJM., Ferrari MD., Pietrobon D. 2009. Enhanced excitatory transmission at cortical synapses as the basis for facilitated spreading depression in $\mathrm{Ca}(\mathrm{v}) 2.1$ knockin migraine mice. Neuron 61:762-73. DOI: 10.1016/j.neuron.2009.01.027.

van Veen E., van der Jagt M., Cnossen MC., Maas AIR., de Beaufort ID., Menon DK., Citerio G., Stocchetti N., Rietdijk WJR., van Dijck JTJM., Kompanje EJO. 2018. Brain death and postmortem organ donation: report of a questionnaire from the CENTER-TBI study. Critical Care 22:306. DOI: 10.1186/s13054-018-2241-4.

Vrselja Z., Daniele SG., Silbereis J., Talpo F., Morozov YM., Sousa AMM., Tanaka BS., Skarica M., Pletikos M., Kaur N., Zhuang ZW., Liu Z., Alkawadri R., Sinusas AJ., Latham SR., Waxman SG., Sestan N. 2019. Restoration of brain circulation and cellular functions hours post-mortem. Nature 568:336-343. DOI: 10.1038/s41586-019-1099-1.

Woitzik J., Hecht N., Pinczolits A., Sandow N., Major S., Winkler MKL., Weber-Carstens S., Dohmen C., Graf R., Strong AJ., Dreier JP., Vajkoczy P., COSBID study group. 2013. Propagation of cortical spreading depolarization in the human cortex after malignant stroke. Neurology 80:1095-102. DOI: 10.1212/WNL.0b013e3182886932.

Woods AT., Velasco C., Levitan CA., Wan X., Spence C. 2015. Conducting perception research

Peer) reviewing PDF | (2019:09:40965:1:1:NEW 26 Oct 2019) 
729

730

731

732

733

734

735

736

737

738

over the internet: a tutorial review. PeerJ 3:e1058. DOI: 10.7717/peerj.1058.

Yang C., Brown RE. 2014. The cholinergic agonist carbachol increases the frequency of spontaneous GABAergic synaptic currents in dorsal raphe serotonergic neurons in the mouse. Neuroscience 258:62-73. DOI: 10.1016/j.neuroscience.2013.11.005.

Yang C-P., Hsieh M-L., Chiang J-H., Chang H-Y., Hsieh VC-R. 2017. Migraine and risk of narcolepsy in children: A nationwide longitudinal study. PLOS ONE 12:e0189231. DOI: 10.1371/journal.pone.0189231.

Youngner S., Hyun I. 2019. Pig experiment challenges assumptions around brain damage in people. Nature 568:302-304. DOI: 10.1038/d41586-019-01169-8. 


\section{Table 1 (on next page)}

Questionnaire on headaches, migraine aura and near-death experiences.

* In contrast to the Greyson Near-Death Experience Scale (GNDES), we also questioned about unpleasant experiences 
1 Table 1. Questionnaire on headaches, migraine aura and near-death experiences. * In contrast to

2 the Greyson Near-Death Experience Scale (GNDES), we also questioned about unpleasant

3 experiences

Questions about headache (adapted from Kaiser et al. (Kaiser et al., 2019))

- Do you get headaches that are NOT caused by a head injury, hangover, or an illness such as the cold or the flu?

- Do your headaches ever last more than four hours?

- Have you ever had visual disturbances around the time of your headache? For example, have you ever seen any spots, stars, lines, flashing lights, zigzag lines, or heat waves?

- Around the time of your headaches, have you ever had: Numbness or tingling of your body or face, weakness of your arm leg, face, or half of your body, difficulty speaking, or none of the above.

Questions about near-death experiences

- Near-death experiences can be defined as any conscious perceptual experience, including emotional, self-related, spiritual and/or mystical experiences, occurring in a person close to death or in situations of intense physical or emotional danger. In plain language - near-death experiences are exceptional experiences that you may have when you are dying or feel as if you were dying. Have you ever had such a near-death experience - either during a true life-threatening event or an event that just felt so?

- Was your near-death experience associated with a true life-threatening event or an event that was not life-threatening but felt so?

- If you wish, please describe your experience (this is optional). We are interested to 
know what you felt, how your experience unfolded over time and in which situation you had your near-death experience.

GNDES (0-2 points for each answer; based on Greyson, 1983 (Greyson, 1983))

1. Did time seem to speed up or slow down?

2. Were your thoughts speeded up?

3. Did scenes from your past come back to you?

4. Did you suddenly seem to understand everything?

5. Did you have a feeling of peace or pleasantness? *

6. Did you have a feeling of joy?

7. Did you feel a sense of harmony or unity with the universe?

8. Did you see, or feel surrounded by, a brilliant light?

9. Were your senses more vivid than usual?

10. Did you seem to be aware of things going on elsewhere, as if by extrasensory perception or telepathy?

11. Did scenes from the future come to you?

12. Did you feel separated from your body?

13. Did you seem to enter some other, unearthly world?

14. Did you seem to encounter a mystical being or presence or hear an unidentifiable voice?

15. Did you see deceased or religious spirits?

16. Did you come to a border or point of no return? 


\section{Table 2 (on next page)}

Selected reports from participants with an experience that reached the threshold of $\geq 7$ points on the Greyson Near-Death Experience Scale (GNDES) and qualified as an NDE.

Note that the last two comments describe experiences during ingestion of ketamine (which has been suggested as the chemical most likely to cause drug-induced near-death experiences (Martial et al., 2019)) and REM sleep disturbance (which has been identified in another recent study as a likely mechanism of near-death experiences (Kondziella, Dreier \& Olsen, 2019) ). Comments are edited for clarity and spelling. 
1 Table 2. Selected reports from participants with an experience that reached the threshold of $\geq 7$

2 points on the Greyson Near-Death Experience Scale (GNDES) and qualified as an NDE. Note

3 that the last two comments describe experiences during ingestion of ketamine (which has been

4 suggested as the chemical most likely to cause drug-induced near-death experiences (Martial et

5 al., 2019)) and REM sleep disturbance (which has been identified in another recent study as a

6 likely mechanism of near-death experiences (Kondziella, Dreier \& Olsen, 2019)). Comments are

7 edited for clarity and spelling.

- [After a suicide attempt] I spend 7 days [in the intensive care unit]. I felt that I did no longer exist in my body; everything went fast as hell and I saw my life [passing before me]. I felt that I was moving but it wasn't like any movement that I had known before. I found myself in the light, a very bright place, the whitest white mixed with energy, as if it was almost alive. I saw three luminous figures coming towards me. I was talking with them without using words; it was much easier and more efficient like talking with feelings and unused senses. All what happened was very personal; I [was being shown images and] received an enormous amount of information, but I am unable to explain it, as if all was spoken to me in a non-existent language that [nobody understands] "here" but everyone once "there". You just KNOW things about yourself, the nature of the world and people. It was beautiful, full of love, and it was so simple. One of the individuals was younger than the others and loved to laugh; it was as if he wanted to say that my suicide attempt wasn't so serious any longer, nor was anything else serious. It also felt like they knew that I wanted to be back - not on earth but somewhere else. 38 years, female, migraine auras (visual, aphasic); NDE 23; lifethreatening

- All pain, fears, worries and suffering disappeared. It was an incredibly pleasant feeling, 
warm and light. I felt unbelievable peace and wanted to remain there, but I was told my moment had not arrived yet and I had to return. When I returned, I felt very secure and knew that death was not to be feared. I remember it as if it was yesterday. 44 years, female; headache without aura; NDE 17; not life-threatening

- My vision became spherical and I could see and understand everything at once. I also felt as if I was speeding towards a light. I knew if I went to the light I wouldn't come back. It took an enormous effort to change direction and get back into my body. 50 years, female; migraine auras (visual, aphasic); NDE 15; not life-threatening

- I was bleeding heavily and began to lose all sense of my physical body. There was this incredible sense of peace and harmony, as if all trouble and stress was gone, and if I just let go, it would never return. I then forced myself to come back to consciousness because I knew I was needed at home. I don't think it lasted more than a minute, but it felt much longer. 56 years, female; migraine aura (visual); NDE 8; life-threatening

- I was almost drowning, when I heard voices in my head telling me how to save myself. My life flashed before my eyes and I saw myself simultaneously being above water level. 25 years, male; migraine aura (visual); NDE 13; life-threatening

- It did feel very real. Like I was hyperaware of everything around me. Things had a glow. Not just the beings but everything had this muted glow. 48 years, female; migraine auras (visual, aphasic); NDE 9; life-threatening

- [During an anaphylactic shock] I saw a brighter and brighter light. I fell on the ground but barely felt my body falling. I couldn't feel anything about my body. The room was still the same but there was a light or white smoke. I saw a beautiful person with blonde, curly and shoulder-long hair. Her face had thin traits. The eyes were looking more like smoke than 
actual eyes. It was a person made of light and colors (like a sort of rainbow or these angels in video clips), protective, smooth, nice, and peaceful. The person couldn't talk but gave me her hand and I started to go with her. Then I felt horrible pain. I briefly felt floating over my body. Then I woke up. I think a saw an angel who was in charge to check if it was my time to go, and if so, to lead me to another place. Maybe it was my deceased 40 years ago grandmother, but I'm not sure. 27 years, female; no headaches; NDE 21; life-threatening

- I was sleeping, and something woke me up. I felt someone watching me, but I was alone. I couldn't breathe. I tried fighting it and felt weird, like I was outside of my body. Time slowed down. Suddenly, it all disappeared. It lasted maybe a minute, but I felt like it was hours. 28years, female, headache without aura; NDE 8; not life-threatening

- My experience was induced by Ketamine at a rave party. 33 years, male, headache without aura; NDE 10; not life-threatening 


\section{Table 3 (on next page)}

Selected reports from participants with an experience below the threshold of $\geq 7$ points on Greyson Near-Death Experience Scale (GNDES) and that did not qualify as an NDE.

Comments are edited for clarity and spelling. 
1 Table 3. Selected reports from participants with an experience below the threshold of $\geq 7$ points

2 on the Greyson Near-Death Experience Scale (GNDES) and that did not qualify as an NDE.

3 Comments are edited for clarity and spelling.

- It was an ordinary circumstance that turned serious quickly. My throat closed and would not open, no matter how much I tried. It closed so long that I started to black out. At first, I was fearful. Then, I remember feeling a great sense of peace and acceptance of death. 33 years, male; headache without aura; NDE 4; life-threatening

- I was in a playground accident aged 12 and drifted in and out of consciousness. Everything seemed to happen incredibly quickly, and I was unable to distinguish between the real emergency respondents and members of family, both deceased and present. I could not feel contact with the ground and believed that I was floating above it. 32 years, male; headache without aura; NDE 6; life-threatening

- I got in the water and suddenly there wasn't anything under my feet, and I was drowning. I saw my life flash quickly before me. It felt very fast but at the same time also very slow. 22 years, female; migraine aura (sensory); NDE 5; life-threatening

- I nearly drowned, and I became incredibly comfortable and at peace with myself. 53 years, male, headache without aura; NDE 6; life-threatening 


\section{Figure 1}

\section{Spreading depolarization occurs both in migraine aura and in the dying human brain.}

Examples from 3 patients with spreading depolarizations. Patient 1 (A-E). Spreading depolarization (SD) is observed as a large negative direct current (DC) shift propagating between different electrodes (A) (subdural full-band DC/alternate current (AC)-electrocorticography (ECoG) between 0 and $45 \mathrm{~Hz}$, electrode separation: $1 \mathrm{~cm}$ ) (Dreier et al., 2017). This short-lasting SD was recorded in a patient with aneurysmal subarachnoid hemorrhage ( $\mathrm{aSAH}$ ) in a metabolically largely intact and sufficiently perfused neocortex region. Based on measurements of regional cerebral blood flow ( $\mathrm{rCBF}$ ) using intracarotid ${ }^{133} \mathrm{Xe}$ and positron emission tomography, blood-oxygen-level dependent (BOLD) imaging with functional magnetic resonance imaging (MRI) and magnetoencephalography (MEG), it is assumed that the SD underlying a migraine aura should be largely similar (Dreier \& Reiffurth, 2015). The patient's perception of a migraine aura is presumably triggered by the SD-induced spreading depression of spontaneous activity (Dreier \& Reiffurth, 2015), which is shown here in (B) and (C) as a transient reduction in amplitudes propagating between electrodes (frequency band: $0.5-45 \mathrm{~Hz}$ ). It should be noted, however, that a patient can only perceive a migraine aura if this spreading depression propagates through an eloquent region of the brain (Dreier \& Reiffurth, 2015). SD is characterized by the almost complete collapse of ion gradients across cell membranes, causing water influx and an almost complete loss of Gibbs' free energy contained in the ion gradients (Dreier et al., 2013). Recovery from SD requires activation of adenosine triphosphate (ATP)dependent membrane pumps, in particular Na,K-ATPases. Therefore, tissue ATP declines by ca. $50 \%$ during SD not only in energy-deprived but also in well-nourished tissue (Dreier \& Reiffurth, 2015). Consequently, rCBF significantly increases (D) in normal tissue to meet the enhanced energy demand and to clear the tissue of metabolites (measurement of rCBF using an optoelectrode and laser-Doppler flowmetry). The regional hyperemia is variably followed by a mild rCBF decrease (oligemia) during which the vascular reactivity is disturbed. The short initial hypoperfusion is an abnormality here that indicates mild impairment of the neurovascular coupling in the context of aSAH (Dreier \& Reiffurth, 2015). The arterial blood pressure (E) measured in the radial artery was stable during the SD. Patient 2 (F-I) . The second patient died from hepatorenal failure several days after aSAH. (Dreier et al., 2018). The circulatory arrest is evidenced by the drop in arterial blood pressure (I). About 35 seconds after the circulatory arrest, the AC-ECoG in traces (G) and $\mathbf{( H )}$ begin to show the non-spreading depression of spontaneous activity. Phase 2 lasts 95 seconds at electrode 2 (H). Thereafter, the terminal SD occurs and spreads further from electrode 2 to electrode 1 (electrode separation: $1 \mathrm{~cm}$ ) (F). Terminal SD consists of the initial SD component and the late negative ultraslow potential (NUP). It remains speculative if NDE can occur in ECoG phases 1, 2 or 3. According to current knowledge, however, the occurrence of NDE in phases 2 or 3 cannot be ruled out. As explained in the main text, ECoG and scalp electroencephalography (EEG) show a flat line in phase 2, but experiments in animals and brain slices with sophisticated electrophysiological techniques including patch-clamping have shown that the synaptic terminals remain highly active in this phase and that the neurons are polarized (Müller \& Somjen, 2000; Fleidervish et al., 2001; Allen, Rossi \& Attwell, 2004; Revah et al., 2016). Therefore, we cannot exclude with certainty that patients may experience a perception at this stage. The terminal depolarization takes place in phase 3. It cannot be excluded either that this may be associated with bright light phenomena or tunnel vision similar to what occurs during a migraine aura. Brain cells die only

Peer] reviewing PDF | (2019:09:40965:1:1:NEW 26 Oct 2019) 
gradually in phase 4 which is characterized by the NUP (F). Patient $\mathbf{3}(\mathbf{J}-\mathbf{Q})$. After onset of the terminal cluster of SDs shown in $(\mathbf{J})$ and $(\mathbf{N})$, this patient with aSAH was found to have lost brainstem reflexes with fixed dilated pupils, indicating the development of brain death (Dreier et al., 2019). The cluster starts here at electrode 1 and propagates to electrode $2(\mathbf{J}, \mathbf{N})$. The first SD occurs in electrically active tissue and therefore causes spreading depression of the spontaneous ECoG activity $(\mathbf{K}, \mathbf{L})$. In contrast to Patient 1 (B, C), however, activity depression then persists (0, P). After the first SD, a second SD occurs, which transforms into a NUP (N). In contrast to Patient 2 (F), further SDs are superimposed on the NUP, but their amplitudes become smaller and smaller (N). Like in patient 1 (E), the arterial blood pressure (Q) remains stable during the SDs and the NUP. The patient was terminally extubated 20 hours later and shortly thereafter a circulatory arrest developed without further SD (Dreier et al., 2019). Data from Patient 2 (Dreier et al., 2018) and Patient 3 (Dreier et al., 2019) are presented here in abbreviated form to illustrate the pivotal aspects of brain death at the tissue level. The figures were not previously published. The patients were enrolled at the Charité - Universitätsmedizin Berlin in research protocols of invasive neuromonitoring approved by the local ethics committee and written informed consent was obtained from the patients' legally authorized representative, as described previously (Dreier et al., 2018, 2019).
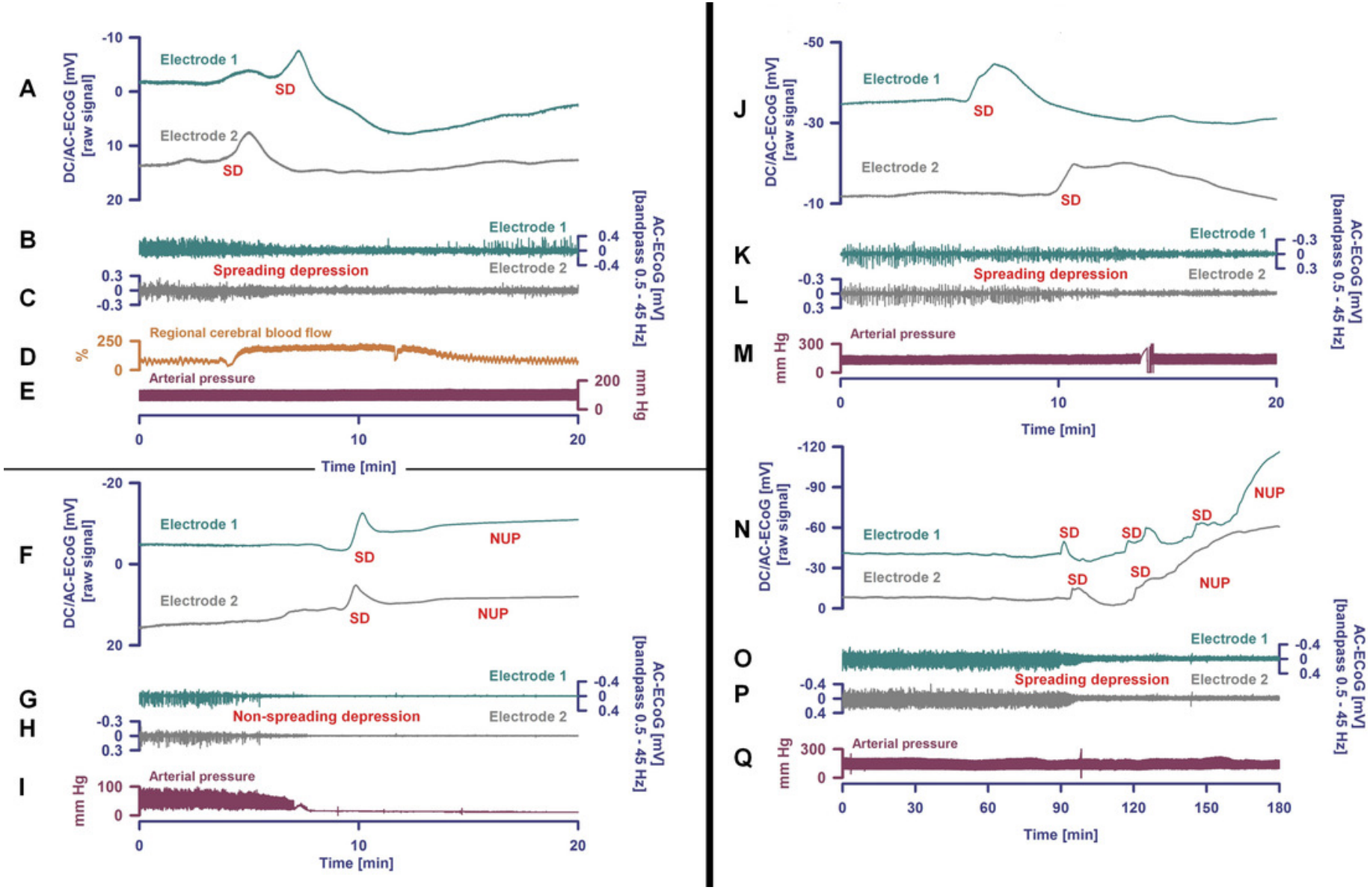
Figure 2

Schematic overview of the study design.

Of 61.707 eligible lay people registered with Prolific Academic ( $h$ ttps://prolific.acl ; accessed on February 4, 2019) , we enrolled 1.037 participants; 81 (7.8\%; C195\% 6.3-9.7\%) of whom reported a near-death experience that fulfilled established criteria (Greyson Near-Death Experience Scale score of 7 or higher). $n=$ number of participants; NDE - near-death experience 


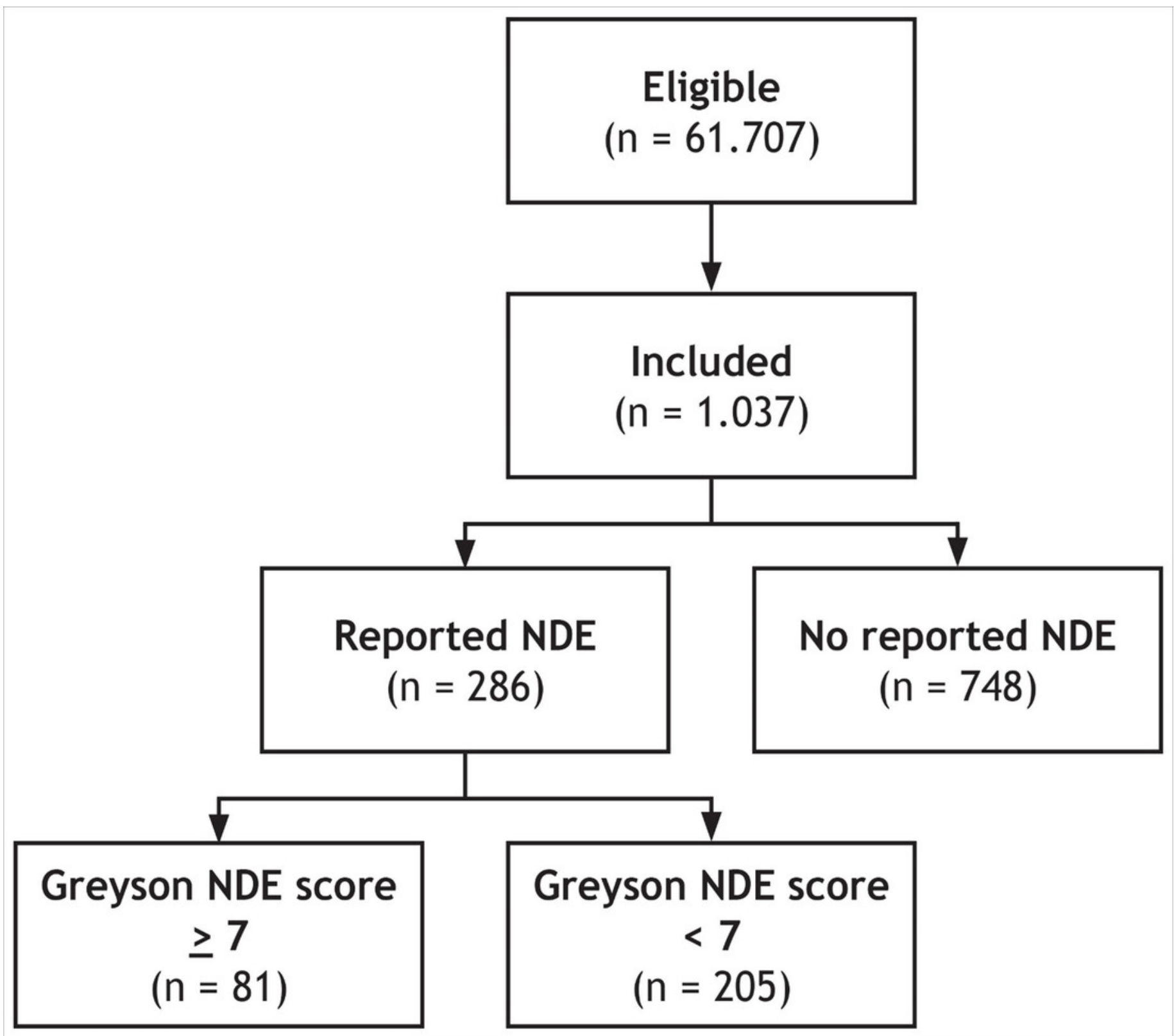




\section{Figure 3}

Experiences of participants with NDE.

This figure illustrates the experiences of 81 participants with NDE confirmed by the Greyson Near-Death Experience Scale (GNDES), i.e. those with 7 points or more on the GNDES. See Table 1 for GNDES questions 1-16. Each question is given 0-2 points ( $0=$ "no"; 1 and $2=$ "yes", weighted according to the intensity of the feature experienced). \# - unpleasant experience (question 5); in contrast to the GNDES, we also inquired about unpleasant experiences

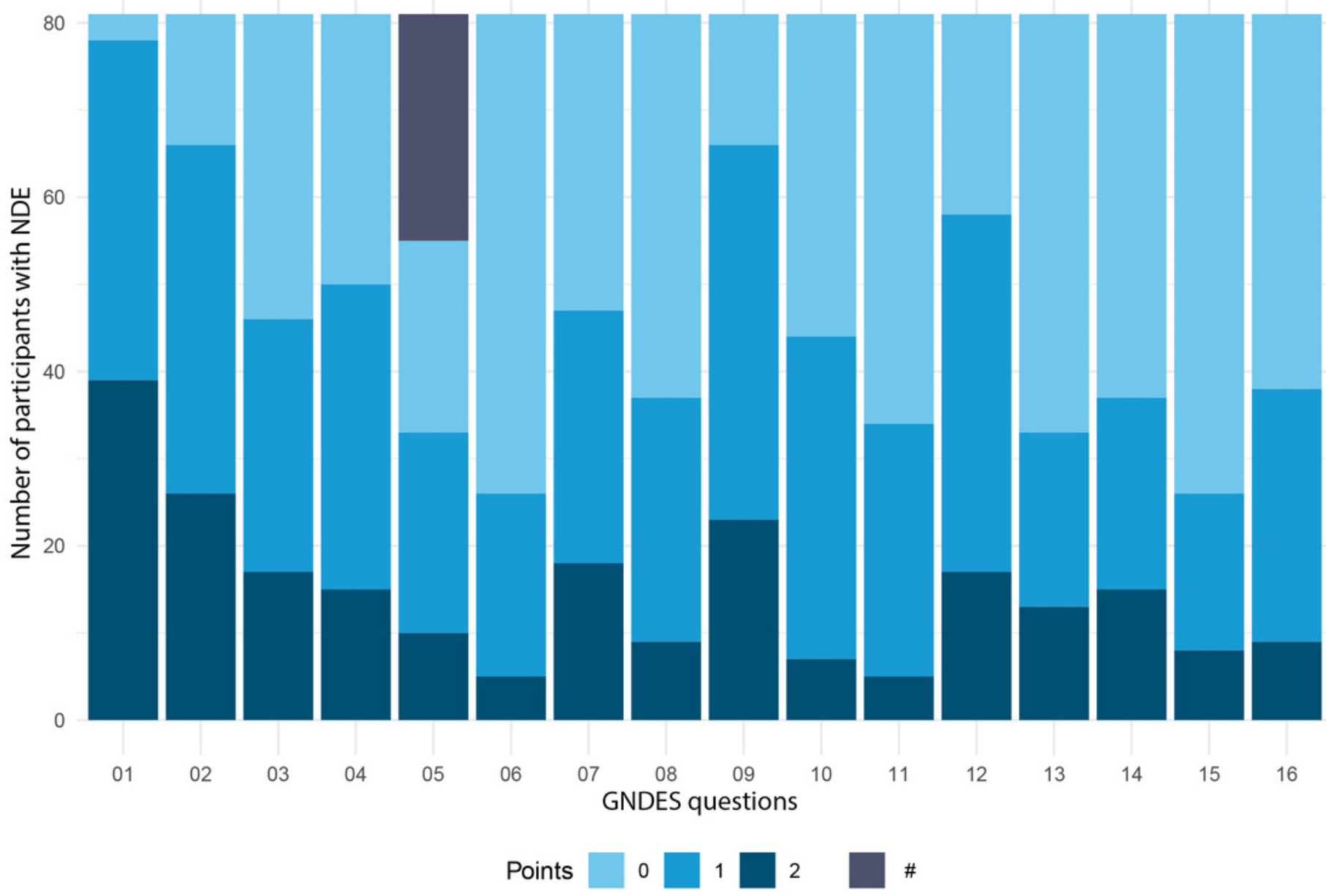

